\title{
Computational Experience With an Algorithm for Finding the $k$ Shortest Paths in a Network*
}

\author{
Douglas R. Shier \\ Institute for Basic Standards, National Bureau of Standards, Washington, D.C. 20234
}

(July 12, 1974)

\begin{abstract}
A particular computer implementation of the Double-Sweep method for calculating the $k$ shortest paths in a network is described. Results are presented for a series of computational experiments performed on rectangular grid networks.
\end{abstract}

Key words: Double-Sweep method; graph; $k$ shortest paths; network; network algorithms; shortest path.

\section{Introduction}

A common task which arises in analyzing a system of interconnected elements or network is that of calculating shortest paths - i.e., routes through the system whose total length or cost is as small as possible. Such calculations occur quite naturally in the context of transportation and communication networks. In applications such as these, it is sometimes desirable to have knowledge of the $k$ shortest paths in contrast to simply a shortest path. For example, the knowledge of good alternative routes (as opposed to just the shortest one) can be used by transportation planners to model more realistically the flow of vehicular traffic on a road network. Or, as a second example, the routing of messages through a communications network when some routes are temporarily obstructed can be based on the best alternative routes which are available.

Several algorithms have been traditionally employed in order to determine the $k$ shortest paths between specified nodes of a network (such paths may in fact contain repeated nodes). An excellent survey of these algorithms is provided by the review article of Dreyfus [1] ${ }^{1}$. More recently, several new methods for performing such calculations have been proposed [2, 4]. These methods are based on a fairly strong analogy which exists between the solution of network path problems and traditional techniques for solving ordinary linear equations. On the basis of preliminary theoretical and computational evidence, one of these (the Double-Sweep method) emerged [4] as a reasonably effective procedure for calculating $k$ shortest paths between a given node and all other nodes in a network. ${ }^{2}$ The purpose of this report is to describe a particular implementation of the Double-Sweep method in FORTRAN V ${ }^{3}$ and to present a body of computational results for a practically important class of networks (namely, those with a rectangular grid topology).

\section{The Double-Sweep Method}

Suppose that $G=(\mathscr{N}, \mathscr{A})$ is a finite directed network in which the real number $l_{i j}$ denotes the length of $\operatorname{arc}(i, j) \epsilon \mathscr{A}$ joining nodes $i, j \in \mathscr{N}$. Node $i$ of the arc $(i, j)$ is said to be incident to

\footnotetext{
AMS Subject Classification: 05035 .

*This work was done while the author was a National Academy of Sciences-National Research Council Postdoctoral Research Associate at the National Bureau of Standards, Washington, D.C. 20234.

${ }^{1}$ Figures in brackets indicate the literature references at the end of this paper.

${ }^{2}$ The algorithms presented in [2] are appropriate for calculating $k$ shortest paths between all pairs of nodes; because of storage limitations, the application of these algorithms is limited to networks having at most a few hundred nodes.
} 
node $j$, while node $j$ is said to be incident from node $i$. A path from node $i$ to node $j$ is an ordered sequence of arcs $\left[\left(i, i_{1}\right),\left(i_{1}, i_{2}\right), \ldots,\left(i_{m-1}, j\right)\right]$ in the network; a path is termed elementary if all nodes appearing along the path are distinct. A circuit is a path whose starting node $i$ and ending node $j$ coincide. The length of a path is defined to be the arithmetic sum of the arc lengths $l_{i j}$ along the path.

The problem under investigation here is that of determining, among all paths extending between two specified nodes, those paths having the smallest, the second smallest, ... and the $k$ th smallest length. It is emphasized that these $k$ shortest paths (that is, paths whose lengths are shortest, second shortest, . . . or $k$ th shortest) are not required to be elementary. The method to be discussed here will allow the calculation of the $k$ shortest paths from a given source node to all other nodes in the network. It is assumed that

(1) All circuits in the network have positive length, and

(2) The network contains no self-loops: that is, circuits of the form $[(i, i)]$.

The Double-Sweep method calculates the $k$ shortest path lengths from a particular source node to all $n$ nodes of the given network by means of alternating forward and backward passes. A precise statement of the method, together with a proof of its validity, can be found in [4]. Basically, the method begins with an initial guess as to the $k$ shortest path lengths and successively improves the current guess to obtain an even better guess. During the forward pass, the current path lengths to each node $j=1, \ldots, n$ are modified by using those nodes $i<j$ which are incident to node $j$. If the sum of a current path length to some node $i$ and the arc length $l_{i j}$ provides a shorter path length to node $j$ than any which is currently known, then the corresponding path lengths to node $j$ are updated to give an improved estimate of the $k$ shortest path lengths. A similar procedure is followed during the backward pass, except that now only nodes $i>j$ are considered with $j=n, \ldots, 1$.

The alternating forward and backward passes are continued until no improvement in the path lengths to any node can be made. Convergence in this sense will always be achieved in a finite number of steps -in fact, in at most $n k+1$ forward and $n k+1$ backward passes. When convergence does obtain, the $k$ shortest path lengths to each node $j$ in the network will have been found. From such path length information, the actual paths corresponding to any of the $k$ shortest path lengths can be determined by a backward path tracing procedure.

In essence, this path tracing procedure is based on the following fact. Namely, if a $t$ th shortest path $\pi$ of length $l$ from node $i$ to node $j$ passes through node $r$, then the subpath of $\pi$ extending from node $i$ to node $r$ is a $q$ th shortest path for some $q, 1 \leqslant q \leqslant t$. This fact can be used to determine the penultimate node $r$ on a $t$ th shortest path of known length $l$ from node $i$ to node $j$. Indeed, any such node $r$ can be found by forming the quantity $l-l_{r j}$ for all nodes $r$ incident to node $j$ and determining if this quantity appears as a $q$ th shortest path length $(q \leqslant t)$ for node $r$. If so, then there is a $t$ th shortest path of length $l$ whose final arc is $(r, j)$; otherwise, no such path exists. This idea is repeatedly used, in the manner of a backtrack program, to produce all paths from $i$ to $j$ with the length $l$, and ultimately all the $k$ shortest paths from node $i$ to node $j$.

It should be pointed out that, while the Double-Sweep method will work perfectly well if circuits of zero length are present, the preceding path tracing procedure may encounter some difficulties if such zero length circuits exist. The essential difficulty is that there can then be an infinite number of paths having the same length, so the generation of all of these paths is clearly impossible. Accordingly, the simple backtracking system described above could possibly cycle indefinitely unless certain precautions are taken. For the sake of retaining simplicity, then, the (quite reasonable) assumption has been made that all circuits have strictly positive length.

\section{Program Implementation}

The calculation of $k$ shortest paths from a particular source node can be accomplished through the use of the four subprograms listed in section 5. The subroutine INPUT allows the description 
of the given network to be entered, the subroutines DSWP and XMULT are used to calculate the $k$ shortest path lengths, and the subroutine TRACE enables the actual tracing out of the $k$ shortest paths. Certain details of the specific implementation used will be discussed in this section.

The first issue concerns the choice of the starting guess with which to initiate the DoubleSweep method, as several choices are possible. It has proved convenient to assign, as the initial approximation, $k$ "infinite" path lengths to each node (the value used for infinity was $I N F=$ 99999999), save for the source node $N S$ which receives the $k$-vector of path lengths $(0, I N F, \ldots$., $I N F$ ). At any step of the process, the $k$-vector associated with each node will contain the $k$ shortest path lengths found so far from node $N S$ to that node. Moreover, these $k$ path lengths are always distinct (apart from infinite values) and are always arranged in strictly increasing order. Such an ordering allows the following two computationally important observations to be made.

(1) If the value $I N F$ is encountered in some component of a $k$-vector, then all subsequent components of the $k$-vector also contain INF values. Therefore, when updating the $k$-vector for node $j$ during a forward or backward pass, the $k$-vector for a node $i$ incident to $j$ need only be scanned as far as the first occurrence of an $I N F$ value since an infinite value cannot possibly yield an improved path length for node $j$.

(2) If $I X V$, the sum of some current path length in the $k$-vector for node $i$ and the arc length $l_{i j}$, is greater than or equal to the maximum element of the $k$-vector for node $j$, then no improvement in the latter $k$-vector by use of the former can possibly be made. Therefore, it is appropriate to keep track of the current maximum element $M A X$ of the $k$-vector for node $j$. If $I X V$ is less than MAX then it is possible for an improvement to be made, as long as the value $I X V$ does not already occur in the $k$-vector for node $j$ (only distinct path lengths are retained).

The use of these two observations allows for a substantial reduction in the amount of computational effort required to update the current path lengths, as compared to the use of some general sorting routine to find the $k$ smallest elements in a list. Since such updating comprises the major computational requirement of the Double-Sweep method, it has proved advantageous to keep the components of each $k$-vector in strictly increasing order. These updating steps, corresponding to appropriate "matrix multiplications" as defined in [4], are performed by the subroutine XMULT, called as required by the subroutine DSWP.

Together, the subprograms DSWP and XMULT enable the calculation of the $K$ shortest path lengths from any given source node $N S$. In some applications, these path lengths may be all the information that is required by the user. In others, the actual paths joining various pairs of nodes are also needed. To accomplish this latter task, the subroutine TRACE is used to produce all paths from node $N S$ to node $N F$ having any of the $K$ shortest path lengths from $N S$ to $N F$. As presently implemented, paths containing up to 5000 arcs will be generated; an error message will indicate when this condition is not fulfilled.

The subroutine INPUT allows a description of the given network to be read in from external unit number 5 together with values for relevant parameters. The network description is achieved by specifying for each arc of the network a record containing its starting node, its ending node and its length. The records are assumed to be sorted in increasing order by arc ending node; moreover, the nodes are assumed to be numbered consecutively from 1 to $N$. The totality of such network description records is followed by a blank record and then a sequence of parameter specification records. Each block of parameter specification records consists of a path calculation record followed by any number, possibly zero, of path tracing records. The path calculation record gives values for $K, N S$ and IMAX. The parameter IMAX is the maximum number of Double-Sweep iterations ${ }^{4}$ allowed before a mandatory termination of DSWP is imposed; for most cases, a value of $I M A X=100$ should suffice. Each path tracing record gives values for $N F$ and $P M A X$, which allow the user to trace out actual paths from node $N S$ to node $N F$ if required; at most $P M A X$ such paths will be determined. Several (but at least one) parameter specification blocks can be accommodated so that various values for $K, N S$ and $N F$ can be explored in the given network. The final record of the input stream is required to be blank.

${ }^{4}$ Each forward or backward pass constitutes an iteration. 
The form of input acceptable to the program can be concisely specified by the following $B N F$ formula system [3].

$$
\langle\text { input }\rangle::=\langle\text { network part }\rangle\langle\text { blank record }\rangle\langle\text { parameter part }\rangle\langle\text { blank record }\rangle
$$

$\langle$ network part $\rangle::=\langle$ arc record $\rangle \mid\langle$ network part $\rangle\langle$ arc record $\rangle$

$\langle$ parameter part $\rangle::=\langle$ parameter block $\rangle \mid\langle$ parameter part $\rangle\langle$ parameter block $\rangle$

$\langle$ parameter block $\rangle::=\langle$ path calcn record $\rangle \mid\langle$ parameter block $\rangle\langle$ path trace record $\rangle$

Definitions for the various records mentioned above are provided below; the columns of a record which are not explicitly mentioned are assumed to be blank.

$$
\begin{aligned}
& \langle\text { blank record }\rangle \text { : } \\
& \langle\text { arc record }\rangle \text { : Cols. } 1-10=\text { Arc Starting Node } \\
& \text { Cols. } 11-20=\text { Arc Ending Node } \\
& \text { Cols. } 21-30=\text { Arc Length } \\
& \text { 〈path calcn record }\rangle \text { : Cols. } 1-5=K \\
& \text { Cols. } 6-10=N S \\
& \text { Cols. } 11-15=I M A X \\
& \langle\text { path trace record }\rangle \text { : Cols. } 1-5=N F \\
& \text { Cols. } 6-10=P M A X
\end{aligned}
$$

The values given to $K, N S, I M A X, N F$, and $P M A X$ are all specified by the user. In addition, the following ranges are assumed for the indicated variables.

$$
\begin{aligned}
N & =\text { number of nodes in the network: } & & 2 \leqslant N \leqslant 1000 . \\
M U & =\text { number of arcs }(I, J) \text { with } I<J: & & 0 \leqslant M U \leqslant 5000 . \\
M L & =\text { number of arcs }(I, J) \text { with } I>J: & & 0 \leqslant M L \leqslant 5000 . \\
K & =\text { number of distinct path lengths required: } & & 2 \leqslant K \leqslant 20 .
\end{aligned}
$$

\begin{tabular}{|c|c|c|c|c|c|c|}
\hline \multirow{2}{*}{ Subprogram } & \multicolumn{4}{|c|}{ Storage for common blocks used } & \multirow{2}{*}{$\begin{array}{l}\text { Program } \\
\text { instruction } \\
\text { storage }\end{array}$} & \multirow{2}{*}{$\begin{array}{l}\text { Total } \\
\text { required } \\
\text { storage }^{a}\end{array}$} \\
\hline & BLKl & BLK2 & BLK3 & BLK4 & & \\
\hline $\begin{array}{l}\text { INPUT .. } \\
\text { DSWP... } \\
\text { XMULT. } \\
\text { TRACE. }\end{array}$ & $\begin{array}{l}22003 \\
22003\end{array}$ & $\begin{array}{l}2 \\
2 \\
2 \\
2\end{array}$ & $\begin{array}{l}20000 \\
20000 \\
20000\end{array}$ & 21001 & $\begin{array}{r}268 \\
267 \\
214 \\
15310\end{array}$ & $\begin{array}{l}43274 \\
42272 \\
20216 \\
56313\end{array}$ \\
\hline AíL.. & 22003 & 2 & 20000 & 21001 & 16059 & 79065 \\
\hline
\end{tabular}

Thus, at most $K=20$ shortest path lengths from a given node in a network with up to 1000 nodes and 10,000 arcs can be handled by the currently programmed version of the algorithm. The approximate storage requirements for the four subroutines comprising the package are given in table 1; the storage requirements appropriate for arbitrary values of $N, K$, and $M=M U+M L$ are given in table 2. If there is insufficient storage available on a particular computer system to retain all the subroutines in core simultaneously, it is possible to break up the execution sequence by performing first the path length calculation (DSWP/XMULT) and next the path tracing calculation (TRACE). This is a feasible strategy because essentially two different network representations are used in these two distinct calculation phases.

TABLE 1. Approximate number of storage locations required by various subprograms

${ }^{a}$ Exclusive of system routines (requiring approximately 5700 locations for the UNIVAC 1108, EXEC 8 operating system used).

\footnotetext{
${ }^{5}$ Only minor program changes are necessary to allow the case $K=1$.
} 
TABLE 2. Approximate number of storage locations required by common blocks and subprograms in terms of $\mathrm{N}, \mathrm{K}$ and $\mathrm{M}=\mathrm{MU}+\mathrm{ML}$

\begin{tabular}{|c|c|c|c|}
\hline \multicolumn{2}{|c|}{ Storage for common blocks } & \multicolumn{2}{|r|}{$\begin{array}{c}\text { Total storage } \\
\text { for subprograms }\end{array}$} \\
\hline $\begin{array}{l}\text { BLK1 } \ldots \ldots \\
\text { BLK2 } \ldots \ldots \\
\text { BLK } 3 \ldots \ldots \\
\text { BLK } 4 \ldots \ldots\end{array}$ & $\begin{array}{c}2 N+2 M+3 \\
2 \\
N K \\
N+2 M+1\end{array}$ & $\begin{array}{l}\text { INPUT } \ldots \ldots \ldots \ldots . \\
\text { DSWP } \ldots \ldots \ldots \ldots \ldots \\
\text { XMULT } \ldots \ldots \ldots \ldots \\
\text { TRACE } \ldots \ldots \ldots \ldots \ldots\end{array}$ & $\begin{array}{c}3 N+4 M+274 \\
N K+2 N+2 M+272 \\
N K+216 \\
N K+N+2 M+15313\end{array}$ \\
\hline & & ALL ....... & $N K+3 N+4 M+16065$ \\
\hline
\end{tabular}

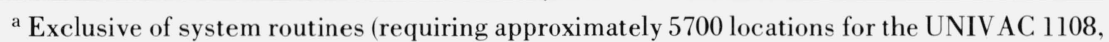
EXEC 8 operating system used).

TABLE 3. Listing of sample card input

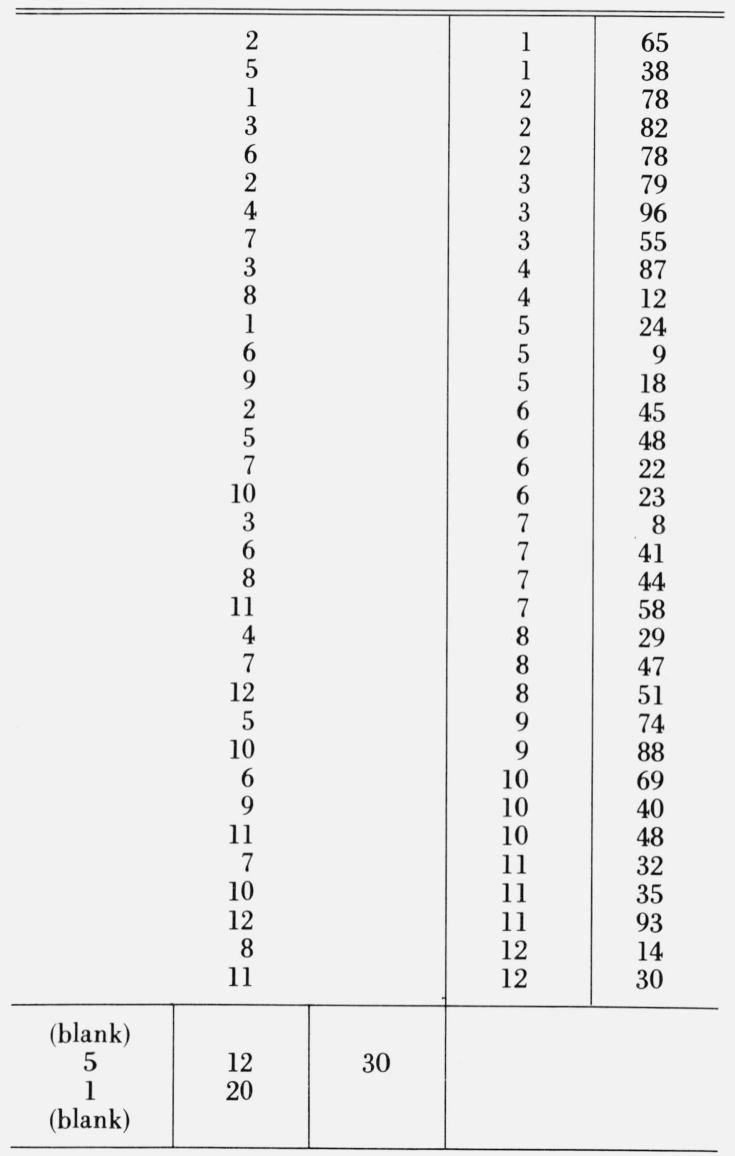

TABLE 4. Listing of sample printed output

\begin{tabular}{c|r|r|l|l|l}
\hline \hline \multicolumn{5}{c}{$K=5$ shortest path lengths from node 12} \\
\hline To node & & & & & \\
1 & 164 & 205 & 211 & 220 & 221 \\
2 & 195 & 232 & 236 & 241 & 242 \\
3 & 150 & 159 & 191 & 200 & 206 \\
4 & 63 & 104 & 128 & 145 & 154 \\
5 & 126 & 167 & 173 & 182 & 183 \\
6 & 117 & 158 & 164 & 173 & 174 \\
7 & 95 & 136 & 151 & 158 & 160 \\
8 & 51 & 92 & 116 & 133 & 142 \\
9 & 200 & 229 & 241 & 247 & 256 \\
10 & 141 & 175 & 186 & 206 & 216 \\
11 & 93 & 127 & 158 & 168 & 176 \\
12 & 0 & 65 & 106 & 123 & 130 \\
\hline
\end{tabular}

Number of iterations required for convergence $=6$

The $K$ shortest paths from node 12 to node 1

\begin{tabular}{c|c|r|r|r|r|r|r|r|r}
\hline Path & Length & \multicolumn{7}{|c}{ Node sequence } \\
\hline 1 & 164 & 12 & 8 & 7 & 6 & 5 & 1 & & \\
2 & 205 & 12 & 8 & 4 & 8 & 7 & 6 & 5 & 1 \\
3 & 211 & 12 & 11 & 10 & 6 & 5 & 1 & & \\
4 & 220 & 12 & 11 & 7 & 6 & 5 & 1 & & \\
5 & 221 & 12 & 8 & 7 & 6 & 5 & 6 & 5 & 1 \\
\hline
\end{tabular}

The output produced from execution of the subroutine DSWP takes the form of a tabular listing of the $K$ shortest path lengths from node $N S$ to all nodes in the network. In addition, the number of Double-Sweep iterations required for convergence of the algorithm is printed. Each time the subroutine TRACE is called, the required $K$ shortest paths (together with their respective lengths) are printed out as the appropriate sequences of nodes leading from $N S$ to $N F$. All printing is assumed to be done through external unit number 6 .

Documented listings of the four subprograms INPUT, DSWP, XMULT and TRACE are given in section 5. Further details about this implementation of the Double-Sweep method, with a path tracing facility, can be obtained by referring to these listings.

Finally, we describe some sample input for the $k$ shortest path package as well as the resulting output. The particular network chosen for illustrative purposes is shown in figure 1. For this net- 
work of 12 nodes and 34 arcs, it is required to find the five shortest path lengths from node 12 to all nodes and the actual paths between node 12 and node 1 . Accordingly, $K=5, N S=12$, and $N F=1$; the values chosen for the other two input parameters are $I M A X=30, P M A X=20$. Table 3 displays the form of card input required for this particular problem. Note that the network description cards are listed in order of increasing arc ending node number. Table 4 displays the resulting output from the computer program.

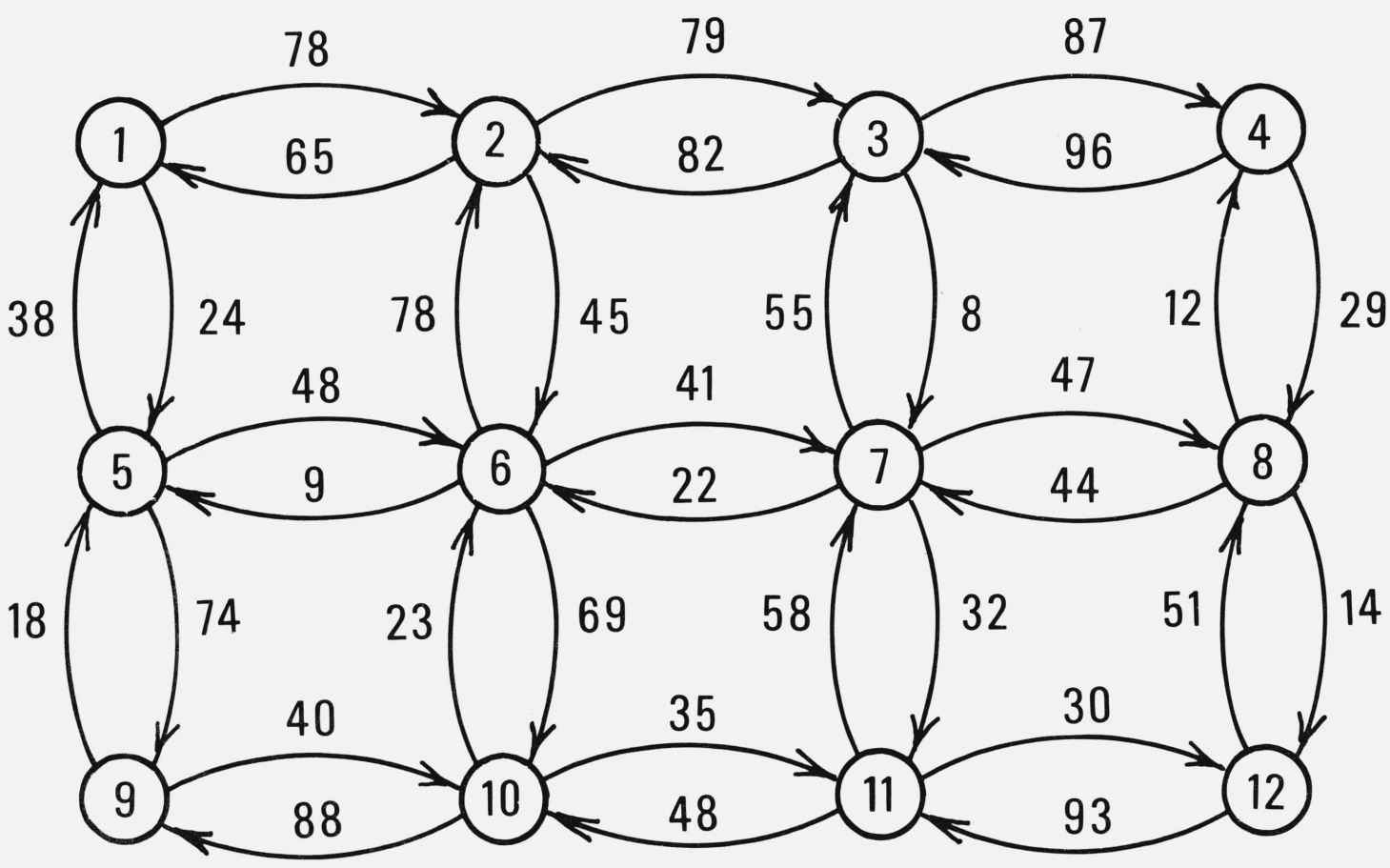

FIGURE 1. An illustrative network.

\section{Computational Results}

The Double-Sweep method has been previously shown [4] to possess certain theoretical and computational advantages over other algorithms for finding the $k$ shortest paths from a given node. The current implementation of this method, embodied in the four subroutines discussed earlier, has undergone testing for a variety of different sample networks. This section will present in particular the results of a number of computational experiments performed on rectangular grid networks. Such networks were chosen for detailed investigation since grid-like networks arise quite frequently in representing, for example, a city street system.

A general $P \times Q$ grid network consists of $N=P Q$ nodes (which are assumed to be numbered consecutively from left to right and top to bottom) and $4 P Q-2(P+Q)$ arcs. The integral lengths of each arc are generated from a uniform distribution over the interval 1 to $R A N G \bar{E}$. (See fig. 1 for an illustrative $3 \times 4$ grid network.) The currently implemented version of the Double-Sweep method was used to obtain the $K$ shortest path lengths from node $N S$ to all nodes of various grid networks; no tracing of paths was considered in these computational experiments. The response characteristics of elapsed computation time on a UNIVAC 1108 were studied as different parameters of the problem were varied. 
First, a series of four $24 \times 24$ grid networks $G_{1}-G_{4}$ were created by drawing four different random samples of arc lengths from the uniform distribution on 1 to 100. Figures 2-4 show how for three distinct source nodes the variation of computation time with $K$ is affected by the particular arc length sample $G_{i}$ chosen. Since the arc length sample chosen does have a noticeable effect on computation time, it was decided that subsequently all results would be averaged over four arc length samples. Figure 5 shows how the average computation time varies, quite nearly quadratically, with $K$ for three distinct source nodes. In fact, table 5 displays the second-degree polynomials which give the best (least squares) fit to the curves of figure 5 over the range $2 \leqslant K \leqslant 20$. From the values obtained for the residual standard deviations, these second-degree polynomials produce an excellent fit to the observations; essentially, then, the average computation time varies quadratically with $K$. Such behavior is not unexpected since the doubling of $K$, for instance, not only increases the computation per iteration (potentially twice as many sums $I X V$ must now be formed for each node) but also tends to increase the number of iterations required for convergence (the equality of $2 k$-vectors automatically ensures the equality of their first $k$ components).

TABLE 5. Best fit second-degree polynomials to figure 5 curves

\begin{tabular}{r|c|c}
\hline \hline NS & $\begin{array}{c}\text { Second-degree fitted } \\
\text { polynomial }\end{array}$ & $\begin{array}{c}\text { Residual standard } \\
\text { deviation }\end{array}$ \\
\hline 1 & $0.8457+0.1616 K+0.0260 K^{2}$ & 0.1369 \\
300 & $1.6111+0.0761 K+0.0425 K^{2}$ & 0.2151 \\
576 & $0.7747+0.1603 K+0.0249 K^{2}$ & 0.1121 \\
\hline
\end{tabular}

${ }^{a}$ Residual standard deviation $=\sqrt{\frac{\sum\left(y_{i}-\hat{y}_{i}\right)^{2}}{n-3}}$. 


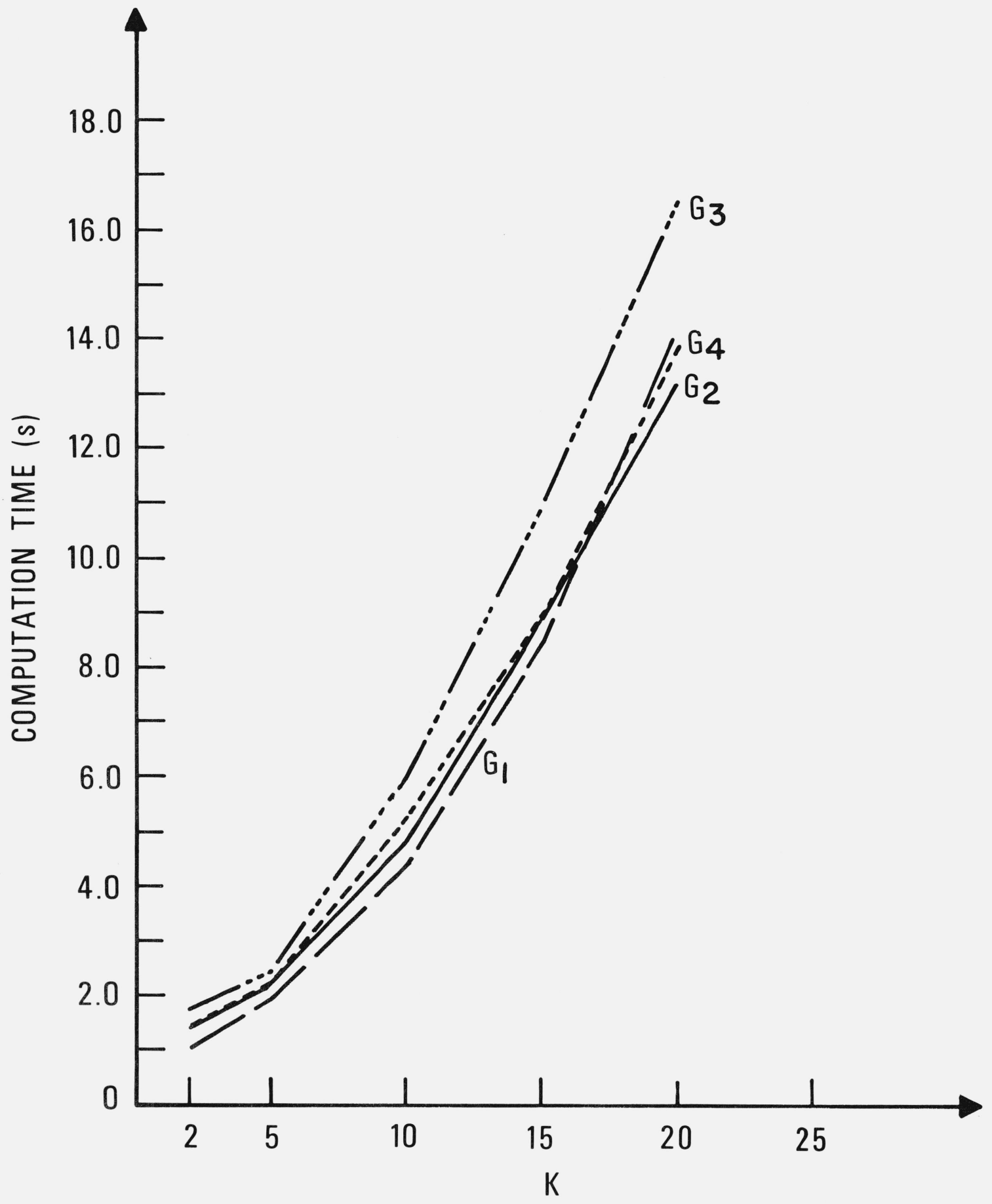

Figure 2. Computation times for four $24 \times 24$ grids ("corner" source node 1 , RANGE =100). 


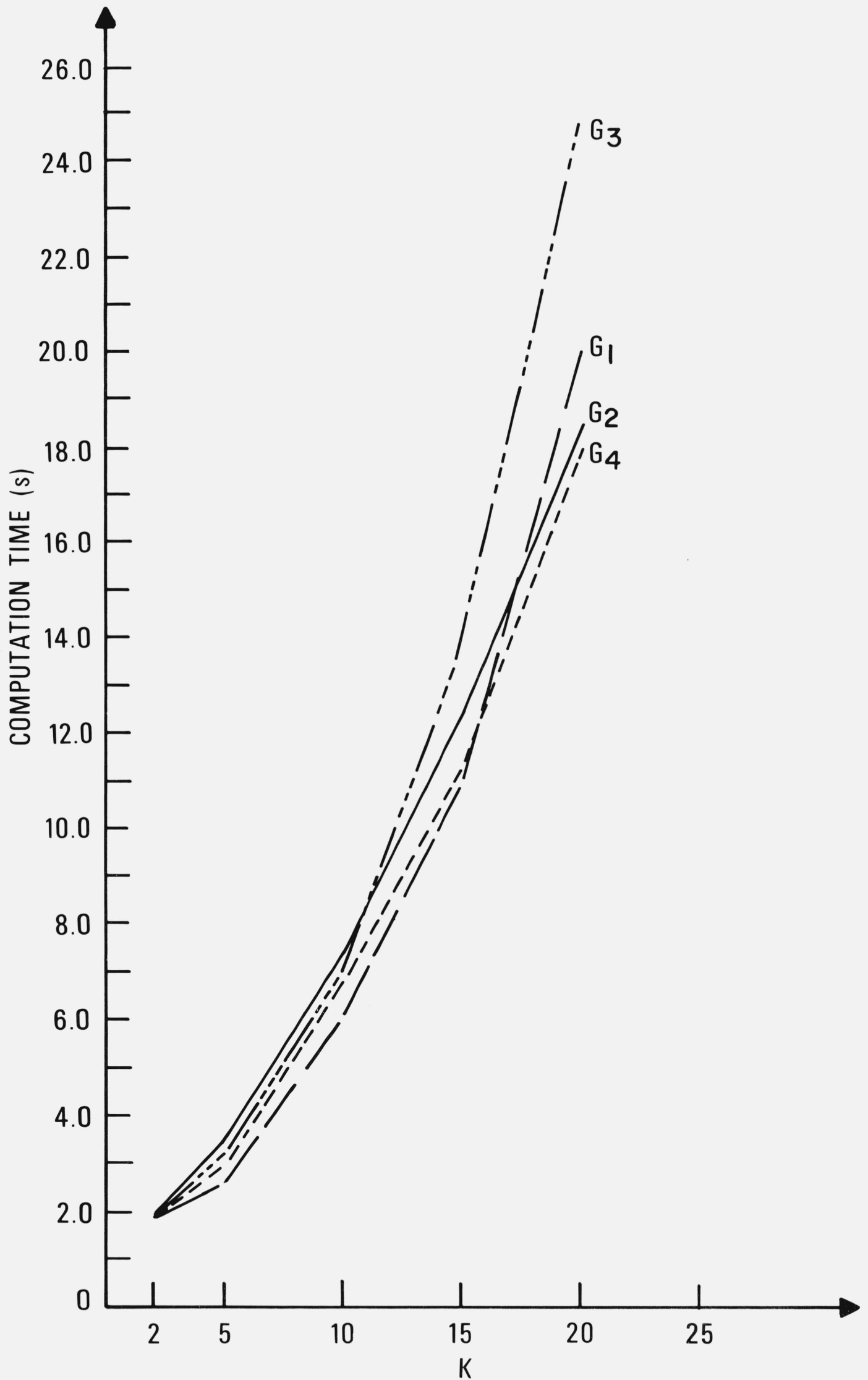

Figure 3. Computation times for four $24 \times 24$ grids ("central" source node 300 , RANGE $=100$ ). 




FigURE 4. Computation times for four $24 \times 24$ grids ("corner" source node 576 , RANGE=100). 


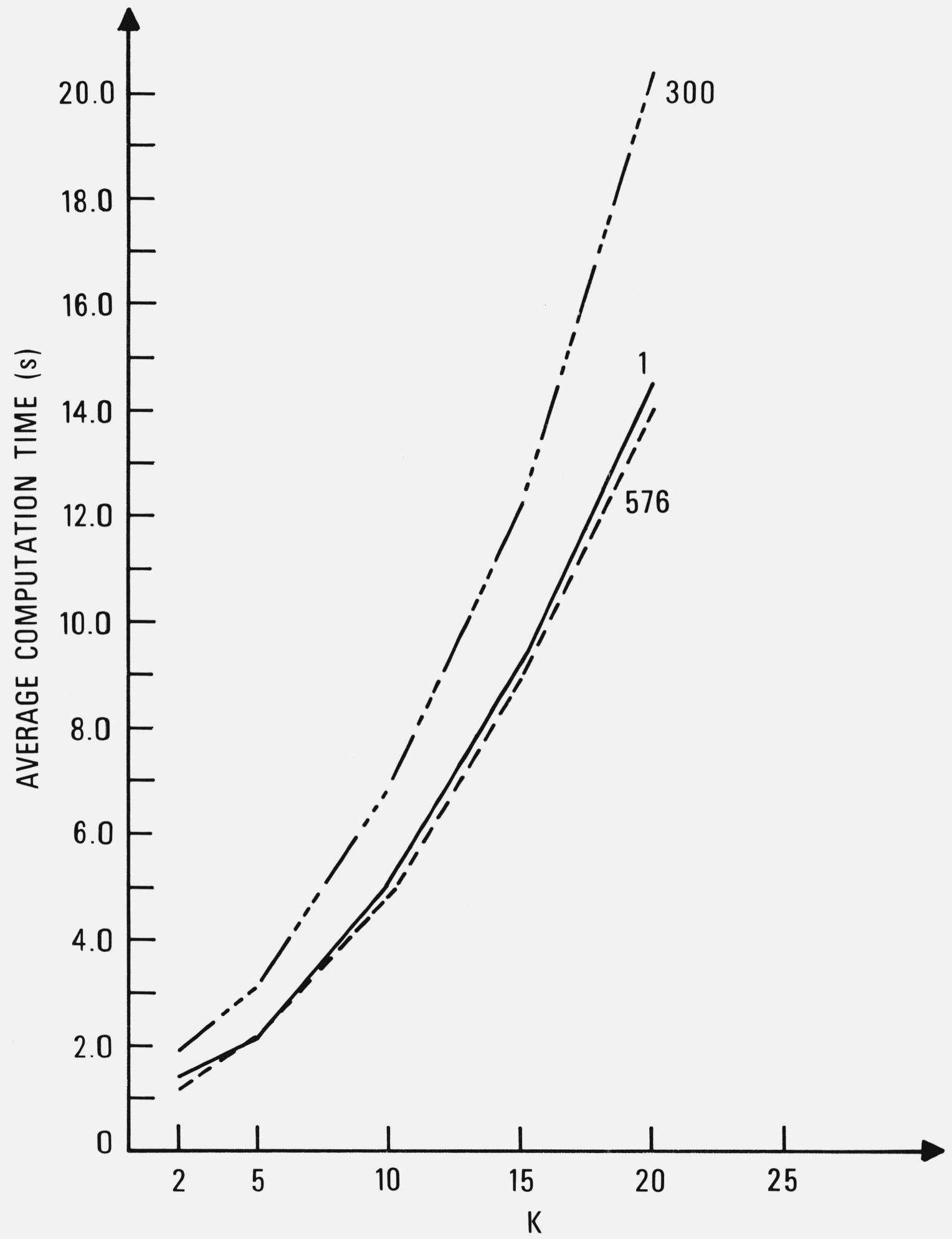

Figure 5. Average computation time for source nodes 1,300, 576 (RANGE $=100)$. 
In addition, figure 5 shows that the average computation time for a centrally located source node $(N S=300)$ is consistently higher than for the boundary nodes $N S=1$ and $N S=576$ (located at the upper left and lower right corners of the grid network). One possible explanation for this observed difference between central and corner nodes is based on the concept of a nonretrograde path in a grid network: that is, a path whose tracing only involves two orthogonal directions (e.g., north and east). A nonretrograde path from node 1 only involves the south and east directions, while a nonretrograde path from node $N$ only involves the north and west directions. On the other hand, a nonretrograde path from a centrally located node can use any pair of orthogonal directions. It has been observed in practice that for grid networks with randomly generated arc lengths a large percentage of the calculated $k$ shortest paths are nonretrograde paths, while the remaining such paths tend to be quite nearly nonretrograde paths. Because the nodes are numbered from left to right and top to bottom, a nonretrograde path from node 1 will have its length correctly assigned in a single forward pass of the Double-Sweep method. Similarly, a nonretrograde path from node $N$ will have its length correctly assigned in a single backward pass. However, a nonretrograde north/ east or south/west path from a centrally located node will generally require several forward and backward passes in order for its length to be correctly determined. For example, in a north/east path each horizontal segment will require a separate forward pass and each vertical segment will require a separate backward pass. Since the processing of nonretrograde (as well as nearly nonretrograde) paths from a centrally located node requires more effort than that for a corner node, it seems reasonable that the calculation of $k$ shortest path lengths for the former should involve more computational effort as compared to the latter type of node.

Another series of grid networks all containing 576 nodes but of differing "shapes" (different ratios of $P$ to $Q$ ) were created for test purposes. With $N S=1$ and $R A N G E=100$, the dependence of average computation time was explored as a function of network shape for different values of $K$. Figure 6 displays the relation between average computation time and $\log (P / Q)$ for $24 \times 24$, $32 \times 18,64 \times 9$, and $144 \times 4$ grid networks. It is apparent that a "square-like" network requires less computation than an "elongated" network, despite the fact that for a given number of nodes a square-like network contains more arcs than an elongated one. A similar relationship between computation time and shape has been observed in $24 \times 24,18 \times 32,9 \times 64$, and $4 \times 144$ grid networks.

In another sequence of test networks with $N=576, N S=1$ and $K=5$, the effect of $R A N G E$ on average computation time was investigated. Four different values of $R A N G E(1,10,100,1000)$ were chosen and the average computation time has been plotted as a function of range for $24 \times 24$ and $144 \times 4$ grid networks (see fig. 7). It is clear that the greater the variability of the arc lengths, the greater the computation time required. As seems reasonable, for larger values of $R A N G E$, the effect is not as radical as for smaller values of $R A N G E$.

Finally, a sequence of square $P \times P$ grid networks was studied with $N S=1, K=5$ and $R A N G E=100$ in order to assess the effect of the number of nodes on average computation time. The parameter $P$ was allowed to assume the values $P=10,15,20,24$ and 30 (producing networks with between 100 and 900 nodes). The influence of this variation in $P$ is seen in figure 8 . Quite surprisingly, in the range $P=15$ to $P=30$ the increase with $P$ is demonstrably linear, with an $R^{2}$ value of 0.988 when a linear regression is performed. Recall that, by contrast, average computation time appears to be quadratically dependent on the parameter $K$.

In sum, then, several series of computational experiments have been performed in order to evaluate the effect of various parameters on computation time, averaged over four different samples from the distribution of arc lengths. The results obtained by varying these parameters can be helpful guidelines when planning computations to investigate changes to a particular network.

In all of the above experiments, the numbering of nodes was taken to be the usual left-to-right, top-to-bottom numbering described earlier. Since each pass of the Double-Sweep method processes the nodes in the fixed order $1, \ldots, N$ (for a forward pass) or the fixed order $N, \ldots, 1$ (for a backward pass), the actual numbering of nodes used can potentially affect the convergence characteristics of this method. Accordingly, a $20 \times 20$ grid network with specific randomly generated arc 
lengths in the range 1 to 100 was investigated for various node numbering schemes. To begin, 10 different randomly generated permutations were used to renumber the nodes of this $20 \times 20$ grid network. The $K=5$ shortest path lengths were calculated from the source node located at the upper left corner of each of the 10 randomly renumbered networks, yielding a mean computation time of $2.488 \mathrm{~s}$ with a standard deviation of $0.220 \mathrm{~s}$. By contrast, when the usual left-to-right, topto-bottom numbering scheme was used, the same $K=5$ shortest path lengths were produced in only $1.213 \mathrm{~s}$, approximately half the average time for randomly numbered networks.

Furthermore, when the nodes were renumbered consecutively from left to right along oddnumbered rows and right to left along even-numbered rows, the required computing time was $1.683 \mathrm{~s}$. On the other hand, when the nodes were renumbered consecutively from top to bottom along odd-numbered columns and bottom to top along even-numbered columns, the required computing time was $1.504 \mathrm{~s}$. The main conclusion to be drawn from such times is that the ordering of nodes can have a pronounced effect on the efficiency of the Double-Sweep method. In particular, a systematic numbering scheme is to be preferred to a random numbering of the nodes. This result accords well with our intuition, since in a systematic numbering scheme the effect of changing the $k$-vector associated with a given node will be passed on rather quickly to some neighboring nodes; there is certainly no guarantee that such will be the case for randomly assigned numbering schemes.

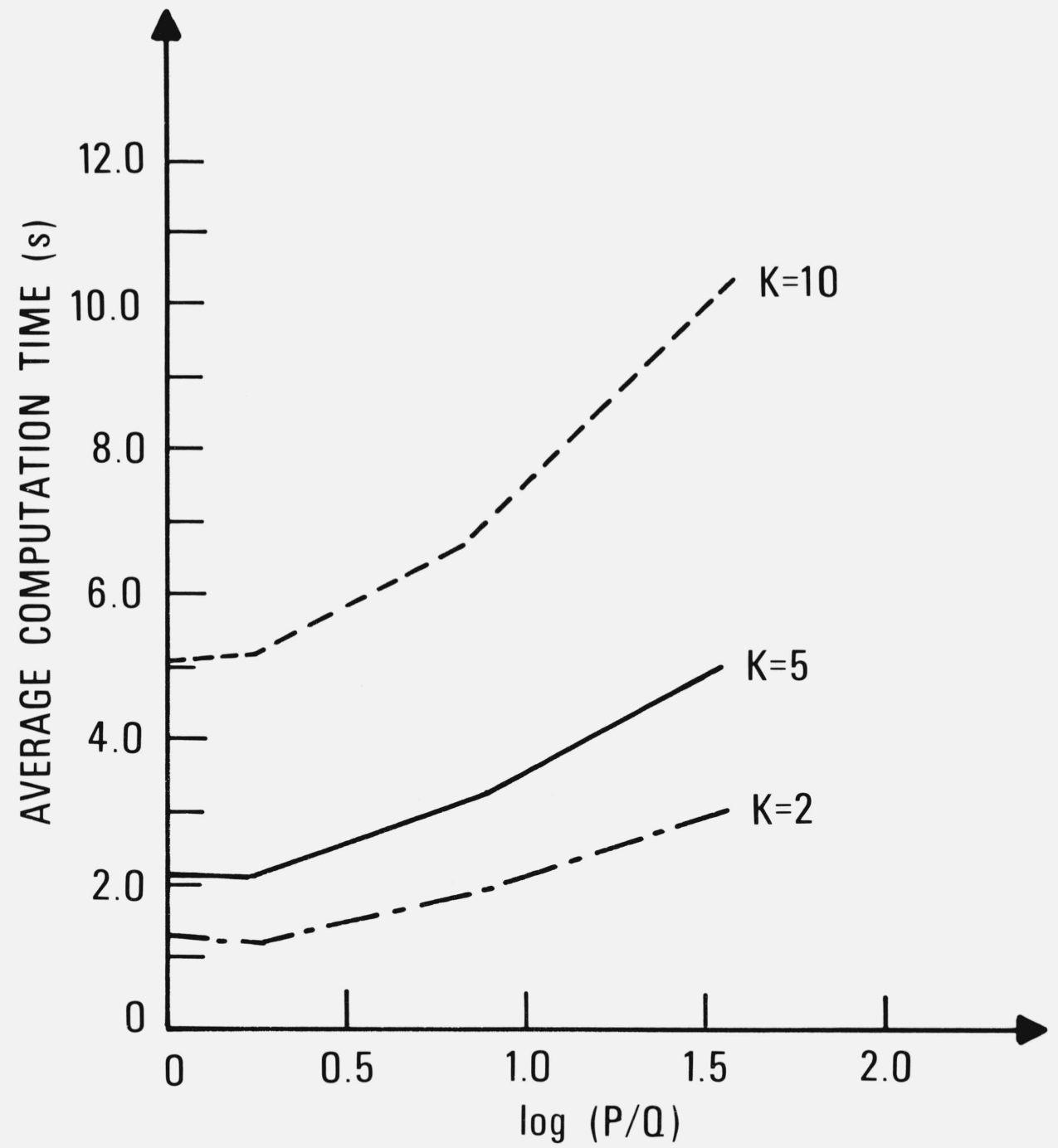

Figure 6. Average computation time for $24 \times 24,32 \times 18,64 \times 9$ and $144 \times 4$ grids $(\mathrm{NS}=1, \mathrm{RANGE}=100, \mathrm{~K}=2,5,10)$. 




FIGURE 7. Average computation time related to RANGE for $24 \times 24$ and $144 \times 4$ grids $(\mathrm{NS}=1, \mathrm{~K}=5)$.

In concluding, some indication will be given of the actual number of iterations required for the Double-Sweep algorithm to converge; recall that each forward or backward pass constitutes an iteration. While the algorithm is guaranteed to converge in at most $2(N K+1)$ iterations [4], this theoretical upper bound usually exceeds the actual number of iterations required by a few orders of magnitude in our sample grid networks. For example, in all of the $24 \times 24$ grid networks generated with $R A N G E=100$ and $N S=1,300,576$ (see figs.2-4), the number of iterations varied from a minimum of 9 (for $K=2$ ) to a maximum of 25 (for $K=20$ ). By contrast, the theoretical upper bounds for these two situations are 2306 and 23,042 iterations, respectively. In the case of $P \times Q$ grid networks with $N=576, N S=1$ and $R A N G E=100$ (see fig. 6), the number of iterations varied from a minimum of 9 (for a $32 \times 18$ grid with $K=2$ ) to a maximum of 37 (for a $144 \times 4$ grid with $K=10$ ); the theoretical upper bounds are 2306 and 11,522, respectively. For the $24 \times 24$ and $144 \times 4$ grid networks with $N S=1$ and $K=5$ (see fig. 7), the number of iterations varied from a minimum of 
5 (for all $24 \times 24$ and $144 \times 4$ grids with $R A N G E=1$ ) to a maximum of 39 iterations (for a $144 \times 4$ grid with $R A N G E=1000$ ); the theoretical upper bound for this situation is 5762 iterations. Finally, even for the 900 node square grids with $N S=1, K=5$ and $R A N G E=100$ (see fig. 8), the number of iterations was at most 19, compared to the theoretical upper bound of 9002 . In all these cases, then, the number of iterations required for convergence is really quite modest; in addition, the theoretical upper bounds are seen to give very little qualitative or quantitative information about the actual number of iterations needed.

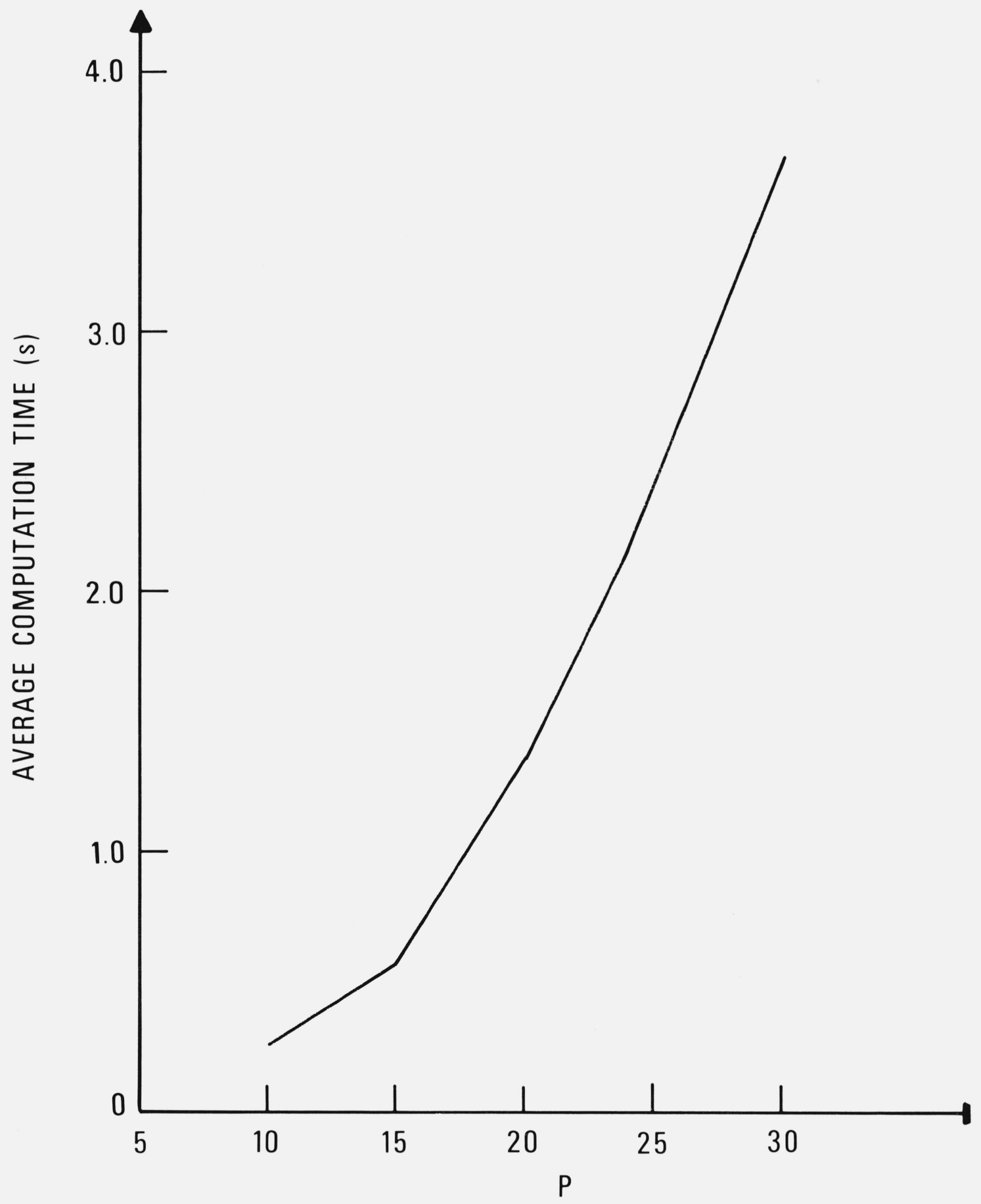

FiguRE 8. Average computation time for five $\mathrm{P} \times \mathrm{P}$ grids $(\mathrm{NS}=1, \overline{\mathrm{RANGE}}=100, \mathrm{~K}=5)$. 


\section{Appendix: Program Listings}

SUBROUT INE INPUT

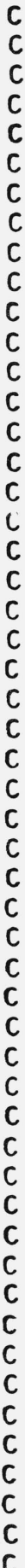

THIS SUBROUT INE INVOLVES THE FOLLOWING INPUT SEQUENCE.

(1) A DESCRIPTION OF THE NETWORK IS READ IN FROM UNIT 5 - THE STARTING NODE, ENDING NODE AND LENGTH FJR EACH ARC. THE ARRAYS AND VARIABLES NEEDED BY SUBROUTINES DSWP, XMULT AND TRACE ARE THEN CREATED.

(2) THE NEXT RECORD READ IN FROM UNIT 5 GIVES VALUES FOR $K$, NS AND IMAX. THE K SHORTEST (DISTINCT) PATH LENGTHS FROM NODE NS TO ALL NODES OF THE NETHORK ARE THEN CALCULATED AND PRINTED THROUGH A CALL OF DSWP.

(3) THE SUCCEED ING INPUT RECORDS READ IN FROM UNIT 5 INDICATE VALUES FOR NF AND PMAX. FOR EACH SUCH RECORD ITHERE MAY BE NONEI THE APPROPRIATE PATHS FROM NS TO NF ARE PRINTED THROUGH A CALL OF TRACE.

SEVERAL SUCCESSIVE INPUT DATA SETS, CONSISTING OF A (2) RECORD POSSIBLY FOLLOWED BY (3) RECORDS, CAN BE ACCOMMODATED. A BLANK RECORD SHOULD PRECEDE AND FOLLOW THE TOTALITY OF ALL SUCH (2), (3) COMB INATIONS. THE NETWORK MUST BE SORTED IN INCREASING ORDER BY ARC ENDING NODE NUMBER. MOREOVER IT IS ASSUMED THAT THE NODES ARE NUMBERED SEQUENTIALLY FROM 1 TO N. ALSO THE NETWORK SHOULD CONTAIN NO SELF-LOOPS AND ALL CIRCUITS IN THE NETWORK ARE REQUIRED TO HAVE POSITIVE LENGTH.

THE VARIABLES AND ARRAYS IN COMMON ARE

$\mathrm{N} \quad=$ THE NUMBER OF NODES IN THE NETWORK.

MU = THE NUMBER OF ARCS $(I, J)$ WITH I LESS THAN J.

$M L=$ THE NUMBER OF ARCS $(I, J)$ WITH J LESS THAN 1 .

LLEN = AN ARRAY WHOSE J-TH ENTRY IS THE NUMBER OF ARCS $(\mathbf{I}, \mathbf{J})$ WITH J LESS THAN I.

LINC = AN ARRAY CONTAINING THE NODES I INCIDENT TO NODE J WITH I GREATER THAN J, LISTED IN OROER OF INCREASING J.

LVAL = AN ARRAY CONTAINING THE ARC LENGTH VALUES CORRESPONDING TO ARCS IN LINC.

ULEN = AN ARRAY WHOSE J-TH ENTRY IS THE NUMBER OF ARCS $(I, J)$ WITH I LESS THAN J.

UINC = AN ARRAY CONTAINING THE NODES I INCIDENT TO NODE J WITH I LESS THAN J, LISTED IN ORDER OF INCREASING J.

UVAL = AN ARRAY CONTAINING THE ARC LENGTH VALUES CORRESPONDING TO ARCS IN UINC.

INF = A NUMBER LARGER THAN ANY PATH LENGTH. A NONEXI STENT PATH IS ASSIGNED THE LENGTH INF.

START = AN ARRAY WHOSE J-TH ELEMENT INDICATES THE FIRST POS ITION ON INC WHERE NODES INCIDENT TO NODE J ARE LISTED.

INC = AN ARRAY CONTAINING NODES I WHICH ARE INCIDENT TO NODE J, LISTED IN ORDER OF INCREASING J.

VAL = AN ARRAY CONTAINING THE ARC LENGTH VALUES CORRESPONDING TO ARCS IN INC.

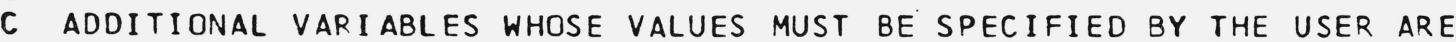




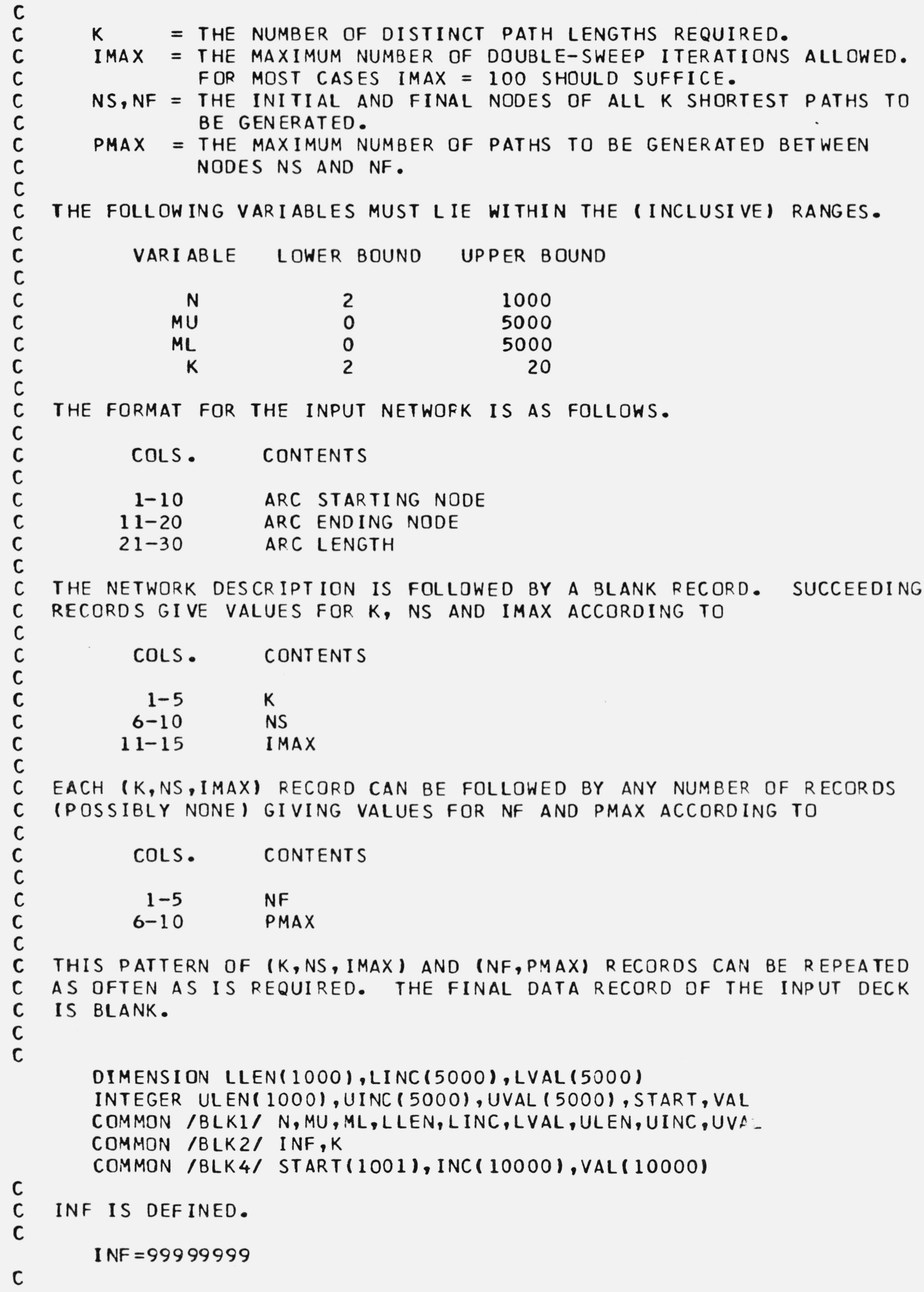


C AS THE INPUT NETWORK IS READ IN, THE VARIABLES AND ARRAYS NEEDED

C BY DSWP AND TRACE ARE CREATED.

C

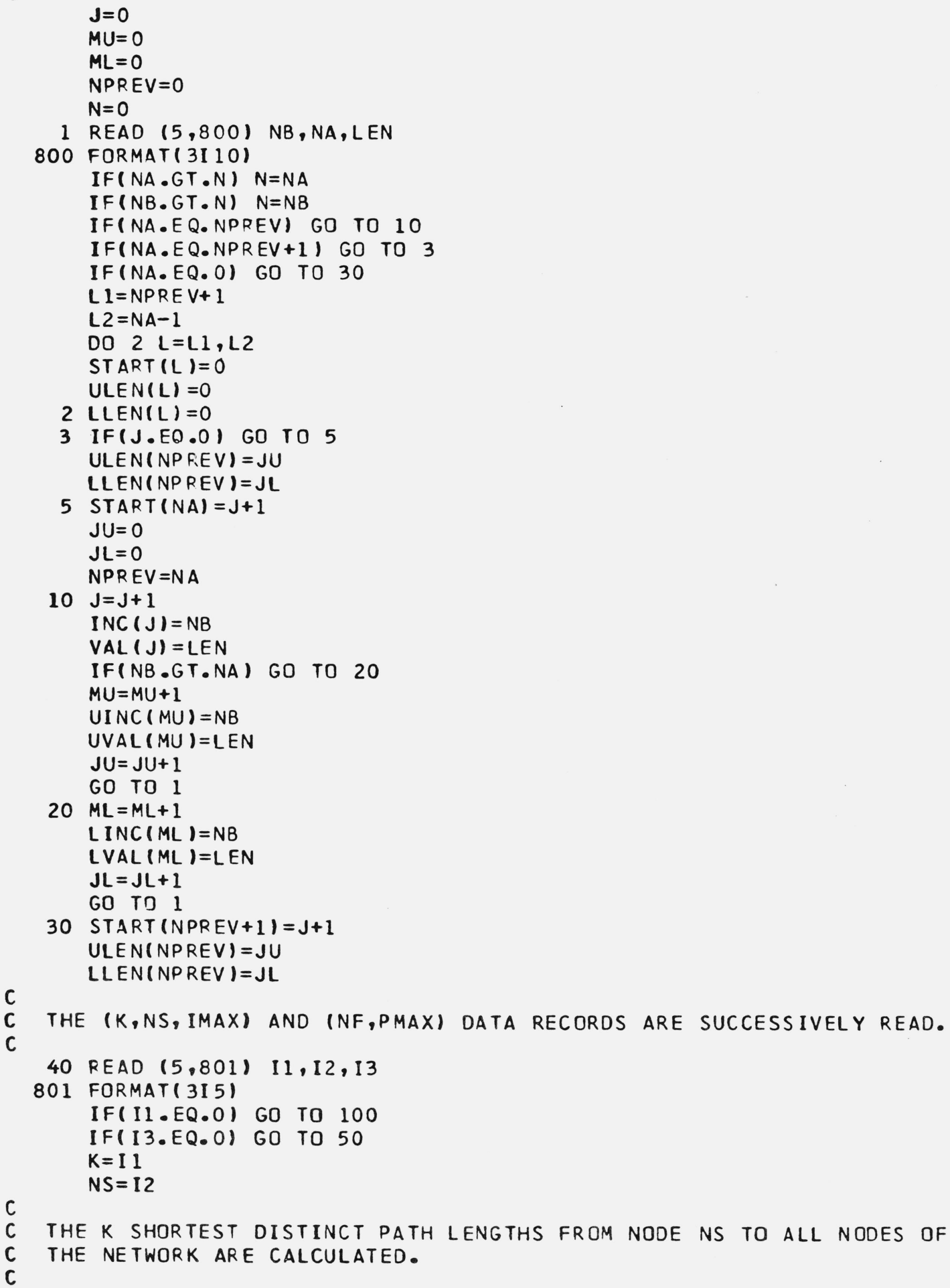


CALL DSWP (NS, 13$)$

GO TO 40

C

C UP TO PMAX OF THE PATHS HAVING THE K SHORTEST PATH LENGTHS FROM NDDE

C NS TO NODE NF ARE DETERMINED.

C

50 CALL TRACE(NS, I1, I2)

GO TO 40

100 RETURN

END 
THIS SUBROUT INE IMPLEMENTS THE DOUBLE-SWEEP METHOD IN ORDER TO CALCULATE THE K SHORTEST (DISTINCT) PATH LENGTHS FROM NODE NS TO ALL NODES OF A NETWORK. THE NETWORK IS ASSUMED TO CONTAIN NO SELF-LOOPS AND ALL CIRCUITS IN THE NETWORK ARE REQUIRED TO HAVE POSITIVE LENGTH. THE REQUIRED K SHORTEST PATH INFORMATION IS PRINTED OUT ON UNIT 6 .

the variables in the calling sequence are

NS = THE NODE FROM WHICH K SHORTEST PATH LENGTHS TO ALL NODES ARE REQUIRED.

IMAX = THE MAXIMUM NUMBER OF DOUBLE-SWEEP ITERATIONS ALLOWED.

THE VARIABLES AND ARRAYS IN COMMON ARE

N = THE NUMBER OF NODES IN THE NETWORK. INODES ARE ASSUMED NUMBERED SEQUENTIALLY FROM 1 TO N.)

MU = THE NUMBER OF ARCS $(I, J)$ WITH I LESS THAN J.

$M L=$ THE NUMBER OF ARCS $(I, J)$ WITH J LESS THAN I.

LLEN = AN ARRAY WHOSE J-TH ENTRY IS THE NUMBER OF ARCS $(I, J)$ WITH J LESS THAN I.

LINC = AN ARRAY CONTAINING THE NODES I INCIDENT TO NODE J WITH I GREATER THAN J, LISTED IN ORDER OF INCREASING J.

LVAL = AN ARRAY CONTAINING THE ARC LENGTH VALUES CORRESPONDING TO ARCS IN LINC.

ULEN = AN AFRAY WHOSE J-TH ENTRY IS THE NUMBER OF ARCS $(I, J)$ WITH I LESS THAN J.

UINC = AN ARRAY CONTAINING THE NODES I INCIDENT TO NODE J WITH I LESS THAN J, LISTED IN ORDER OF INCREASING J.

UVAL = AN ARRAY CONTAINING THE ARC LENGTH VALUES CORRESPONDING TO ARCS IN UINC.

INF = A NUMBER LARGER THAN ANY PATH LENGTH. A NONEXISTENT PATH IS ASSIGNED THE LENGTH INF.

$K$ = THE NUMBER OF DISTINCT PATH LENGTHS REQUIRED .

$X \quad=\quad A N$ ARRAY WHOSE $(I, J)-T H$ ENTRY WILL EVENTUALLY CONTAIN THE J-TH SHORTEST (DISTINCT) PATH LENGTH FROM NODE NS TO NODE I.

ADDITIONAL VARIABLES ARE

ITNS = THE NUMBER OF ITERATIONS PERFORMED.

INDX = A VAR IABLE RETURNED FROM XMULT WHICH = 1 IF CONVERGENCE HAS OBTAINED AND = O OTHERWISE.

THE FOLLOWING VARIABLES MUST LIE WITHIN THE (INCLUSIVE) RANGES

VARIABLE LOWER BOUND UPPER BOUND

$\begin{array}{lll}N & 2 & 1000 \\ \text { MU } & 0 & 5000 \\ \text { ML } & 0 & 5000\end{array}$




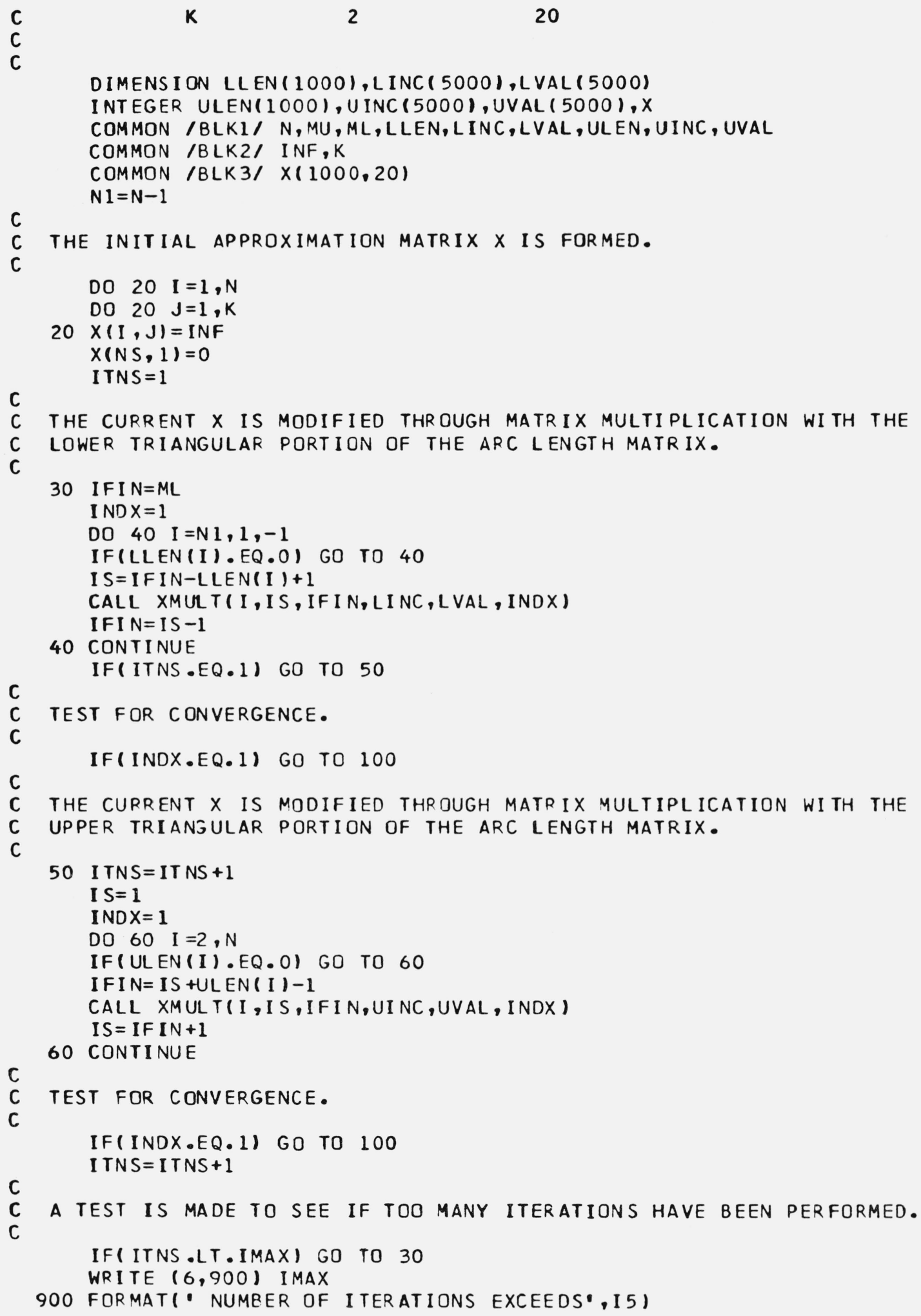




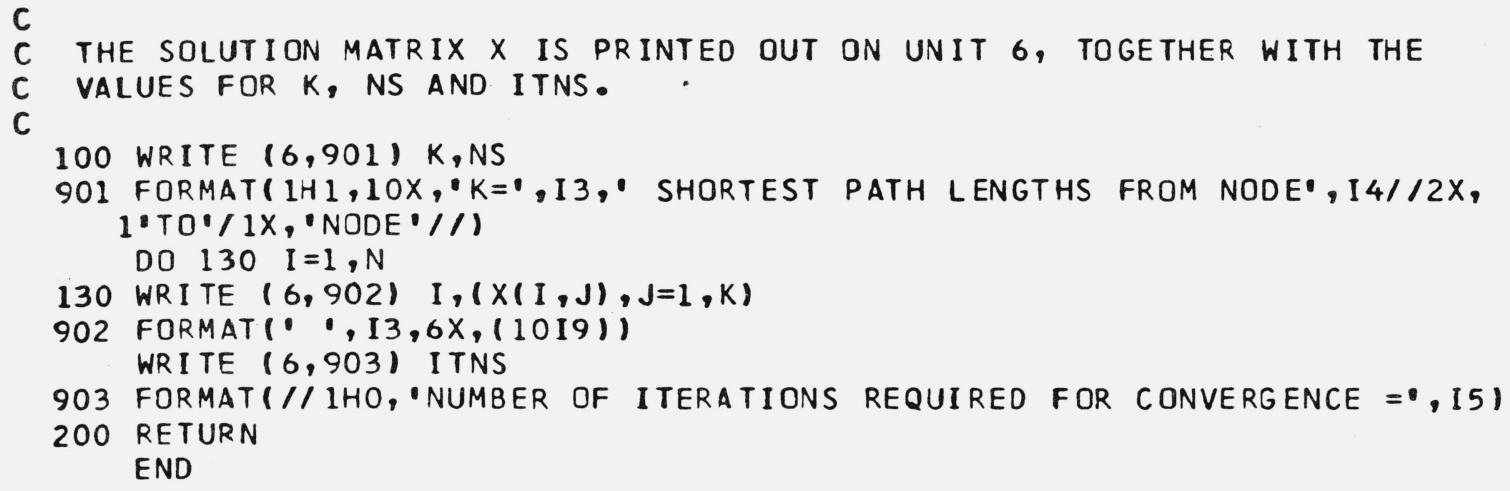


C

C

C

C

C

C

THIS SUBROUTINE WILL PERFORM THE APPROPRIATE MATRIX MULTIPLICATION OF $X$ BY THE I-TH COLUMN OF THE LOWER (OR UPPER) PORTION OF THE ARC LENGTH MATRIX. IN EFFECT, THE CURRENT K SHORTEST PATH LENGTHS ASSOCIATED WITH NODE I TRE ADJUSTED BY CONSIDERING NODES WHICH ARE INCIDENT TO NODE I. IF AN IMPROVEMENT CAN BE MADE, THE VARIABLE INDX WILL RETURN WITH THE VALUE 0 .

THE VARI ABLES AND ARRAYS IN THE CALLING SEQUENCE ARE

I = THE COLUMN OF THE ARC LENGTH MATRIX TO BE MULTIPLIED ON THE LEFT BY $X$ • THE CURRENT K SHORTEST PATH LENGTHS TO NODE I WILL BE IMPROVED IF POSSIBLE.

IS = THE STARTING POSITION IN LISTS INC AND VAL WHERE ARC INFORMATION FOR NODE I CAN BE FOUND.

IFIN = THE FINAL POSITION IN LISTS INC AND VAL WHERE ARC INFORMATION FOR NODE I CAN SE FOUND.

INC = AN ARRAY CONTAINING NODE INCIDENCE INFORMATION, EITHER LINC OR UINC.

VAL = AN ARRAY CONTAINING ARC LENGTH INFORMATION, EITHER LVAL OR UVAL.

INDX = A VARIABLE WHICH IS SET EQUAL TO 0 IF AN IMPROVEMENT CAN BE MADE IN THE K SHORTEST PATH LENGTHS TO NODE I.

THE VARIABLES AND ARRAYS IN COMMON ARE

INF = A NUMBER LARGER THAN ANY PATH LENGTH. A NONEXISTENT PATH IS ASSIGNED THE LENGTH INF.

$K$ = THE NUMBER OF DISTINCT PATH LENGTHS REQUIRED .

$X$ = THE CURRENT APPROXIMATION MATRIX FOR K SHORTEST PATH LENGTHS FROM A GIVEN NODE TO ALL NODES OF THE NETWORK.

ADDITIONAL VARIABLES AND ARRAYS ARE

A = AN AUXILIARY APRAY USED IN FINDING THE K SMALLEST DISTINCT ELEMENTS OF A SET.

MAX = THE CURRENT MAXIMUM ELEMENT OF ARRAY A.

IXV = A FEASIBLE PATH LENGTH TO NODE I FROM THE GIVEN NODE.

DIMENSION INC(5000)

INTEGER VAL (5000), A(20), X

COMMON /BLK2/ INF,K

COMMON /BLK3/ X(1000,20)

INITIALIZE A TO THE CURRENT K SHORTEST PATH LENGTHS FOR NODE I, IN STRICTLY INCREASING ORDER.

DO $10 \mathrm{~J}=1, \mathrm{~K}$

$10 A(J)=X(I, J)$

$M A X=A(K)$ 


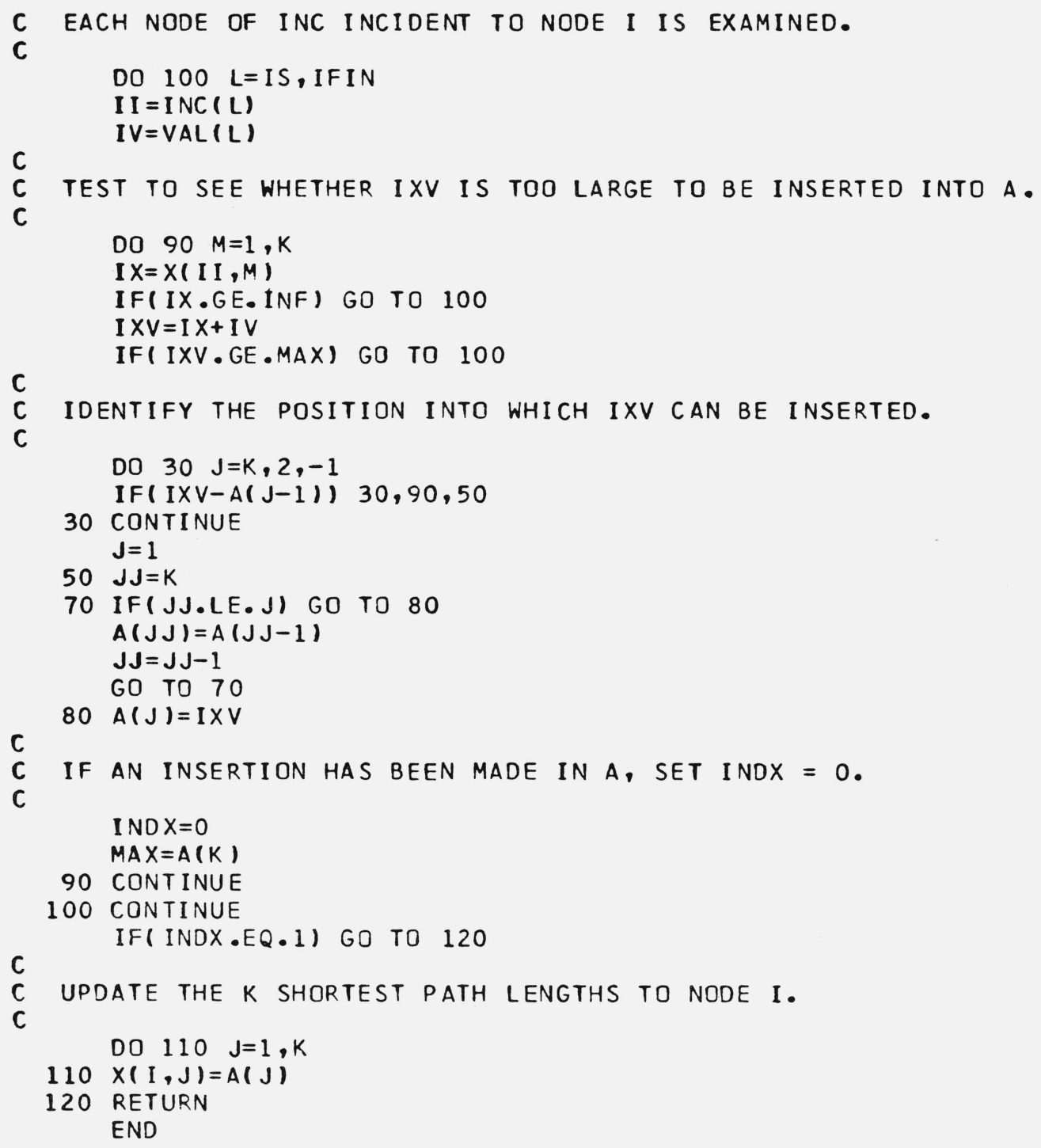


THIS SUBROUTINE WILL TRACE OUT THE PATHS CORRESPONDING TO THE $K$ DISTINCT SHORTEST PATH LENGTHS FROM NODE NS TO NODE NF. AT MOST PMAX SUCH PATHS WILL BE GENERATED. IT IS ASSUMED THAT ALL CIRCUITS IN THE NET WORK HAVE POSITIVE LENGTH. MOREOVER ONLY PATHS HAVING AT MOST 5000 ARCS WILL BE PRODUCED. AN ERROR MESSAGE WILL INDICATE WHEN THIS CONDITION IS NOT FULFILLED. THE REQUIRED PATHS BETWEEN NODES NS AND NF ARE PRINTED OUT ON UNIT 6.

THE VARIABLES IN THE CALLING SEQUENCE ARE

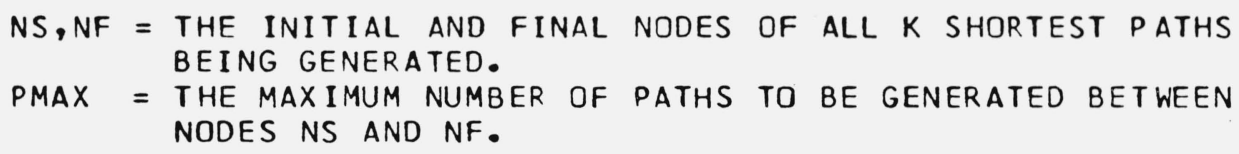

THE VARIABLES AND ARRAYS IN COMMON ARE

INF = A NUMBER LARGER THAN ANY PATH LENGTH. A NONEXI STENT PATH IS ASS IGNED THE LENGTH INF.

$K \quad=$ THE NUMBER OF DISTINCT PATH LENGTHS REQUIRED. K SHOULD LIE IN THE RANGE 2 TO 20 INCLUSIVE.

$X \quad=$ AN ARRAY WHOSE $(I, J)-T H$ ENTRY IS THE J-TH SHORTEST (DISTINCT) PATH LENGTH FRTM NODE NS TO NODE I.

START = AN ARRAY WHOSE J-TH ELEMENT INDICATES THE FIRST POSITION ON INC WHERE NODES INCIDENT TO NODE J ARE LISTED.

INC = AN ARRAY CONTAINING NODES I WHICH ARE INCIDENT TO NODE J, LISTED IN ORDER OF INCREAS ING J.

VAL = AN ARRAY CONTAINING THE ARC LENGTH VALUES CORRESPONDING TO ARCS IN INC.

ADDITIONAL VARIABLES AND ARRAYS ARE

JJ = INDEX OF THE PATH LENGTH FROM NS TO NF BEING EXPLORED. JJ CAN TAKE ON VALUES FROM 1 TO $K$.

NP = THE NUMBER OF PATHS FROM NS TO NF FOUND.

KK = CURRENT POSITION OF LIST P.

$P=$ AN ARRAY CONTAINING NODES ON A POSSIBLE PATH FROM NS TO NF.

$Q \quad=$ AN ARRAY WHOSE I-TH ELEMENT GIVES THE POSITION, RELATIVE TO START, OF NODE P(I) ON THE INC LIST FOR P(I-1).

PV = AN ARRAY WHOSE I-TH ELEMENT IS THE ARC LENGTH EXTENDING FROM NODE P(I) TO NODE P(I-1).

INT EGER P(5000), Q(5000), PV $(5000)$, START, VAL, X, PMAX

COMMON /BLK2/ INF, K

COMMON /BLK3/ X(1000,20)

COMMON /BLK4/ START(1001), INC(10000),VAL(10000)

$c$
$C$

INITIALIZATION PHASE.

DO $10 I=1,5000$ 







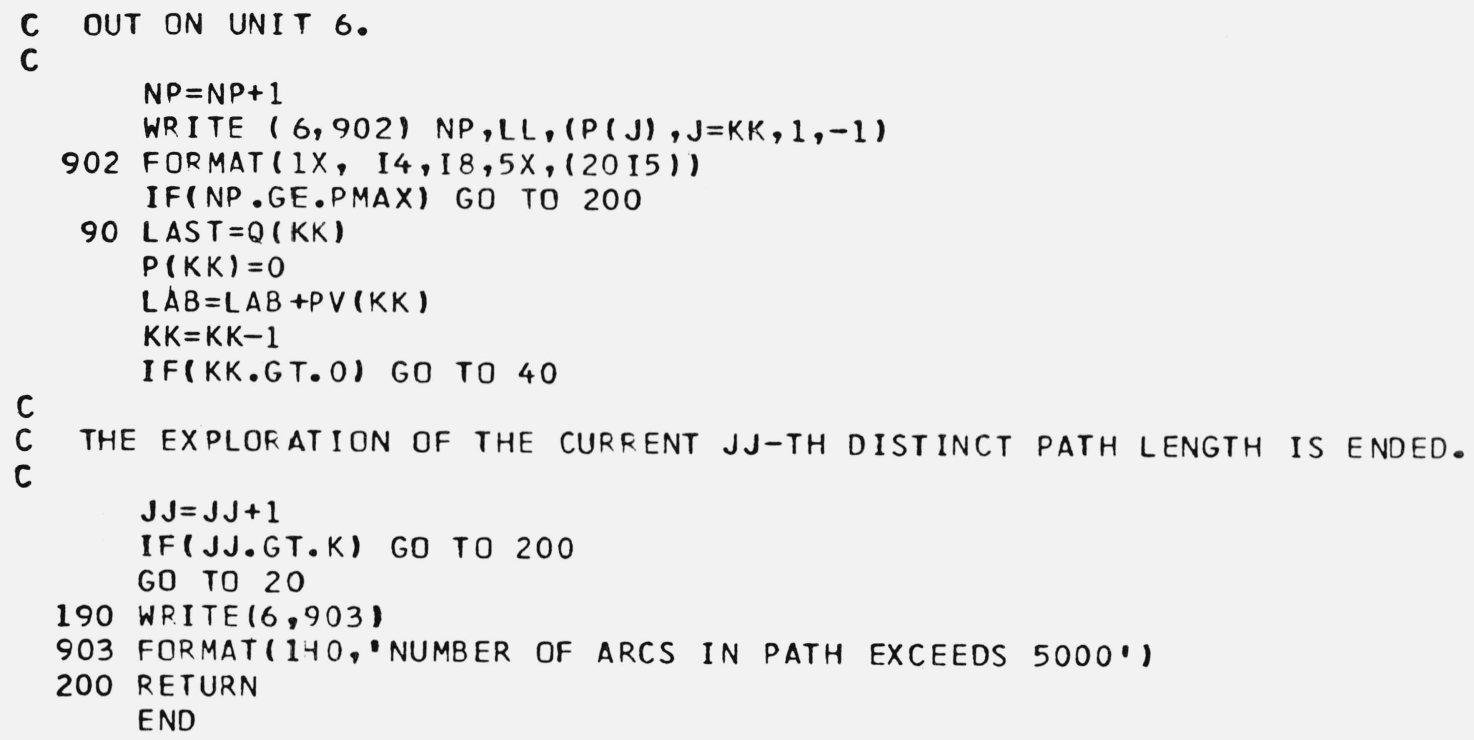

\section{References}

[1] Dreyfus, S., An Appraisal of Some Shortest-Path Algorithms, Operations Res. 17,395-412 (1969).

[2] Minieka, E., and Shier, D., A Note on an Algebra for the $k$ Best Routes in a Network, J. Inst. Maths Applics 11, 145-149 (1973).

[3] Rosen, S. (editor), Programming Systems and Languages, Ch. 2B (McGraw-Hill Book Co., New York, 1967).

[4] Shier, D., Iterative Methods for Determining the $k$ Shortest Paths in a Network, submitted for publication.

(Paper 78B3-410) 